Radioprotection, Suppl. 1, vol. 40 (2005) S27-S32

(C) EDP Sciences, 2005

DOI: 10.1051/radiopro:2005s1-005

\title{
Radioactive particles released from various nuclear sources
}

\author{
B. Salbu and O.C. Lind \\ Isotope Laboratory, Department of Plant and Environmental Sciences, Agricultural University \\ of Norway, 1432 Aas, Norway
}

\begin{abstract}
Radionuclides released to the environment may be present in different physico-chemical forms, ranging from ionic species to colloids, particles and fragments. Following releases during nuclear events such as nuclear weapon tests or use of depleted uranium munitions, and from nuclear accidents associated with explosions or fires, radionuclides such as uranium and plutonium are predominantly present as particles, mainly fuel particles. Similarly, radioactive particles are present in effluents from reprocessing facilities, and radioactive particles are observed in sediments in the close vicinity of radioactive waste dumped at sea. Thus, releases of radioactive particles occur far more often than earlier anticipated.

Soils and sediments can act as a sink for colloids, particles and fragments, while contaminated soils and sediments may also act as a potential diffuse source, depending on particle characteristics and processes influencing particle weathering and remobilisation of associated radionuclides. To assess long-term impact from radioactive particle contamination, information on the source term is essential, i.e. activity concentrations and isotopic ratios as well as the particle size distribution, crystallographic structures and oxidation states influencing particle weathering rates and the subsequent mobilisation and biological uptake of associated radionuclides. The activity concentrations and the isotopic ratios will be source dependant, while particle characteristics will also reflect the release scenario, dispersion processes and deposition conditions. The present paper will summarise information on various nuclear sources summarise having released radioactive particles in the past.
\end{abstract}

\section{INTRODUCTION}

Radionuclides released from a source may be present in different physico chemical forms such as low molecular mass (LMM) species, colloids and pseudocolloids, aerosols, particles as well as fragments. According to [1], radioactive particles in the environment are defined as localised aggregates of radioactive atoms that give rise to an inhomogeneous distribution of radionuclides significantly different from that of the matrix background. Particles in the aquatic environment are defined as entities having diameters larger than $0.45 \mu \mathrm{m}$, while in air these entities are referred as aerosols. Colloids or pseudo- colloids are defined as localised heterogeneities ranging in size from $1 \mathrm{~nm}$ to $0.45 \mu \mathrm{m}$, while LMM refer to species less than $1 \mathrm{~nm}$ or molecular mass less than $1 \mathrm{kDa}$. As radioactive particles ranging from colloids to fragments are inhomogeneously distributed in a matrix such as soils, sediments and waters, identification of localised heterogeneities indicates the presence of particle [2].

A significant fraction of refractory radionuclides released by high temperature nuclear events, such as nuclear weapons tests and accidents in nuclear reactors is associated with fuel particles. In addition, radioactive particles have been released under low temperature conditions such as atmospheric emission during normal operations, and in authorised effluents from nuclear installations. Particles containing refractory radionuclides are formed due to critical or subcritical destruction of fuel matrices (e.g., explosions, fires, corrosion processes), cluster formation, condensation processes or interactions with available surfaces during release and dispersion. Releases of particles from 
nuclear installations during normal operation are due to insufficient clean up of effluents or insufficient filtering of air emissions. The activity concentration and activity ratios of matrix elements and refractory radionuclides reflecting burn-up (e.g. actinides) are source-specific, while specific release conditions may influence the activity concentrations of volatiles (e.g. ${ }^{137} \mathrm{Cs}$, ${ }^{90} \mathrm{Sr}$ ) and particle characteristics such as particle size distributions, crystallographic structures and oxidation states.

Radioactive particles released from a source and deposited in the environment represent point sources of short- and long-term radioecological significance. Direct effects relate to internal doses following inhalation of respiratory particles, as well as skin doses received from surface contamination. Long-term effects relate to ecosystem transfer of radionuclides remobilised from radioactive particles over time, due to weathering. Thus, information on particle characteristics influencing weathering rates (e.g., size, structure, oxidation states) and subsequent radionuclide remobilisation is essential for long-term environmental impact assessments [2], but is usually ignored within most monitoring and assessment programmes.

\section{METHODS APPLIED FOR THE CHARACTERISATION OF PARTICLES}

Radioactive particles deposited in the environment are inhomogeneously distributed. As samples collected may not be representative of the bulk [3] and the sample dissolution may be incomplete [4], localised heterogeneities of radionuclides represent a radioanalytical challenge. According to IAEA [1] "The failure to recognize the heterogeneity of radionuclide distribution in the environment leads to analytical inconsistencies, irreproducible results, and erratic conclusions”. Consequently the estimated inventories of particle-contaminated areas may be underestimated.

To obtain information on radioactive particle characteristics, fractionation techniques are usually needed prior to the characterisation of particles [2]. To separate particles in air, cascade impactors with membranes having different cut-off levels ( $\mu \mathrm{m}$ to $\mathrm{mm}$ ) are frequently used. For particles and colloids in waters, filtration $(0.45 \mu \mathrm{m})$ and tangential flow systems (nm to $\mu \mathrm{m}$ range membranes) are applicable. Using autoradiography, images of localised heterogeneities reflect the presence of particles in soils, sediments and biota. Following the application of non-destructive measurement techniques (e.g., gamma-, beta- or alpha-spectrometry), individual particles can be separated for further analysis. In scanning electron microscopy (SEM) using backscattered electrons, information on particle size distribution and structure as well as the distribution of high atomic elements on particle surfaces can be obtained. By X-ray mapping, the $2 \mathrm{D}$ distribution of individual elements associated with particle are obtained, while semi-quantitative elemental analysis at specific particle sites is obtained by X-ray microanalysis [5]. Using solid-state speciation techniques, e.g. synchrotron radiation (SR) X-ray microscopic techniques, information on 2D or 3D distribution of elements within particles (X-ray absorption/fluorescence), crystallographic structures (micro-X-ray diffraction) and oxidation states of matrix elements (micro-X-ray absorption near edge spectroscopy, $\mu$-XANES) can be obtained [6].

\section{SOURCES OF ARTIFICIALLY PRODUCED RADIOACTIVE PARTICLES}

\subsection{Particles released during nuclear weapons tests}

More than 2000 nuclear weapons tests have been performed globally since 1945, in the atmosphere, at ground, under ground, and under water. In addition, a series of safety trials as well as peaceful underground nuclear explosions (PUNE) has been performed. Releases of radioactive particle from atmospheric and surface ground nuclear weapons tests are well documented from Nevada Test Site, US; Marshall Islands; Semipalatinsk, Kazakhstan; Maralinga, Australia; Mururoa, French Polynesia. For other test sites (e.g. in China, India, Pakistan) information on particle releases is not available in open literature.

Marshall Island (1946-1958): Following the nuclear weapons tests at the Bikini and Enewetak atolls 
and the Marshall Islands, hot spots or localised heterogeneities in soils have been identified [7] as well as pure Pu particles varying in size (up to $\mathrm{mm}$ ) surrounded by coral matrix. Based on autoradiography, large spherical particles $(0.5-1 \mathrm{~mm})$ with uniformly distribution of radionuclides and irregular several mm-sized particles with surface contamination were observed after ground-surface shots. According to Crocker et al. [8], particle characteristics (size distribution, shape, colour) depended on devices and shot conditions. Pu associated with spherical particles from high altitude shots was inert in water, while Pu particles associated with debris from coral-surface bursts were relatively soluble in water.

Nevada test site (1951-1962): Following the nuclear tests, hot spots and localised heterogeneities in soil reflecting the presence of radioactive particles are reported [9]. A variety of fused or partially fused Pu-particles and large agglomerates consisting of individual small particles differing in colour, specific activity, density and magnetic properties have been identified. The particle size distribution depended on device and shot conditions; at high altitudes spherical small-sized dense particles with activity distributed throughout the particles were obtained, while at ground surface large irregular shaped particles with lower density and specific activities were observed [8]. Leaching of gross gamma/beta activity from particles depended on device and shot conditions, matrix, particle size and type; beta emitters in airburst debris were dissolved in $0.1 \mathrm{M} \mathrm{HCl}$.

Maralinga, Australia (1953-1963): Following particularly the 12 safety trials, where more than $20 \mathrm{~kg}$ of $\mathrm{Pu}$ and about $20 \mathrm{~kg}$ of $\mathrm{U}$ were dispersed by conventional explosives, Pu was predominantly present as particles; up to several hundred microns, finely dispersed Pu particles and Pu-contaminated soil particles [e.g., 10]. Most of the activity was associated with particles within the 250-500 $\mu \mathrm{m}$ fraction; while $5 \%$ of the total mass had diameters less than $45 \mu \mathrm{m}$, and a respiratory fraction (less than $7 \mu \mathrm{m}$ ) was identified. In addition to $\mathrm{Pu}$ and $\mathrm{U},{ }^{241} \mathrm{Am}$ was also associated with particles. Leaching experiments using a simulated lung fluid demonstrated the presence of inert particles with low solubility.

Semipalatinsk, Kazakhstan (1949-1989): Following the nuclear weapons tests relatively large (several hundred $\mu \mathrm{m}$ ) radioactive particles containing $\mathrm{Pu}$ and $\mathrm{U}$ have been identified at Ground Zero. $\mathrm{Pu}$ associated with particles or fragments with activity levels exceeding $50 \mathrm{kBq} \mathrm{kg}^{-1}$ have also been reported [11]. Following the use of PUNEs for crater formations (e.g. Tel'kem-1 and Tel'kem-2 crater lakes), radioactive particles containing $\mathrm{U}$ and $\mathrm{Pu}$ have been characterised (unpublished).

Mururoa, French Polynesia (1966-1996): Following the nuclear weapons tests and particularly the weapons trials using conventional explosives at Mururoa (Colette region) Pu particles with activities 5-30 kBq (up to $1 \mathrm{MBq}$ ) ranging from $200 \mu \mathrm{m}$ to several hundred $\mu \mathrm{m}$ were identified [12]. Using optical microscopy and X-ray micro-fluorescence for analysis of 200-500 $\mu \mathrm{m}$ particles, large differences in the surface structures could be observed; from glassy relatively smooth compact surfaces to conglomerates of small particles with rough appearances. Leaching experiments using human serum demonstrated the presence of inert particles with low solubility; less than $0.07 \%$ of the particle content [12].

Novaya Zemlya (1950s-1990): Following the nuclear tests significant contamination of actinides and fission products has been localised to the 3 major test areas, and the presences of radioactive particles has been claimed. Following underwater weapons tests in the Chernaya Bay, localised radioactivity and sample heterogeneity reflecting the presence of particles have been reported [13].

\subsection{DU particles released from depleted uranium (DU) munitions}

Following the 1999 Balkan conflict, depleted U particles ranging from submicrons to about $30 \mu \mathrm{m}$, with average size of $2 \mu \mathrm{m}$, i.e. respiratory particles have been identified $[14,15]$. $U$ in the DU particles was oxidized to $\mathrm{UO}_{2}$ or $\mathrm{U}_{3} \mathrm{O}_{8}$ ). Following the Golf war, DU particles ranging from submicrons to several hundred micrometers were observed [16]. The median particle size depended on sources and sampling sites; small-sized oxidized $\mathrm{U}$ particles as $\left(\mathrm{UO}_{2}, \mathrm{U}_{3} \mathrm{O}_{8}\right.$ or a mixture of these oxidized forms, similar to that observed in Kosovo, were identified in swipes and in soils collected 
below DU penetrators. Larger particles with $U$ present in oxidation state +5 and +6 , were associated with fire in a DU ammunition storage facility [16].
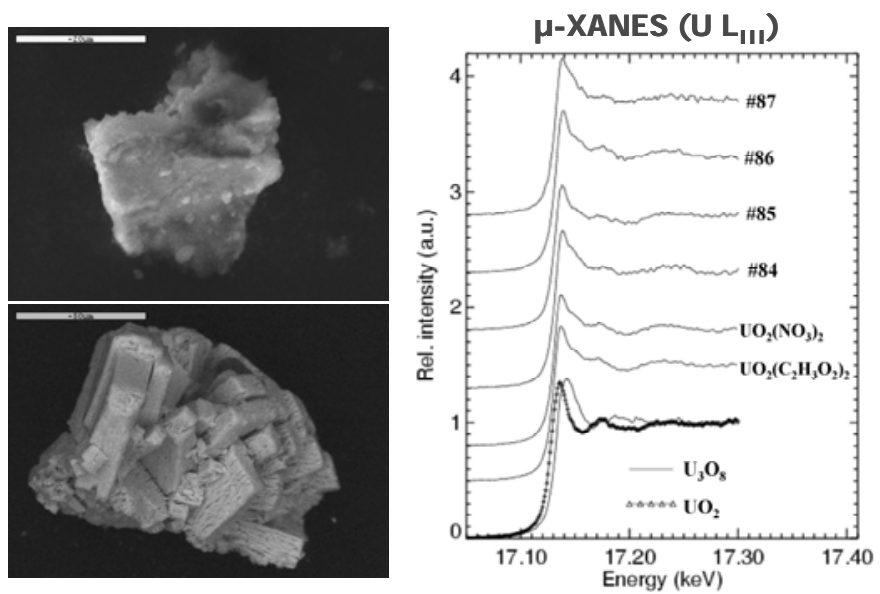

Figure 1. Depeleted uranium particles from Kuwait. Upper left: $\mathrm{UO}_{2}$ particle originating from impact with tanks; Lower left: Highly oxidised yellow particle (ox. state +6 ) from munition storage fire; Right: XANES profiles of samples and standards [16].

\subsection{Particles releases due to accidents with nuclear devices}

Palomares, Spain (1966): Following the crash of US B52 aircraft carrying 4 thermonuclear weapon submicron particles up to mm-sized particles containing ${ }^{239} \mathrm{Pu}$ were dispersed over terrestrial areas [17]. Using synchrotron radiation microtechniques, oxidised Pu-U particles have been identified [unpublished].

Thule, Greenland (1968): Following the crash of US B52 aircraft carrying 4 nuclear weapons ${ }^{239} \mathrm{Pu}$ from the 4 weapons was dispersed and deposited on ice-covered areas and in sediments. The particle size distribution varied, from submicrons to large low-density inert particles and the median size was about $2 \mathrm{~mm}$ [13]. Due to the presence of inert Pu-particles in the sediments, the inventory based on leached sediment samples has probably been underestimated [18]. Using synchrotron radiation microtechniques, oxidised Pu-U particles have been identified [unpublished].

Canada (1978): The re-entry of the reactor driven Soviet satellite Cosmos 954 contributed to radioactive debris, with radioactive components ranging from submicrons to fragments. About $25 \%$ of the inventory was estimated as mm sized radioactive particles. Only a fraction of the total mass was, however, recovered [13].

\subsection{Particles released during nuclear accidents}

Except for the Windscale fire and the Chernobyl accident, most of the nuclear site accidents have had a local impact only (e.g. Johnston Atoll and Rocky Flats, USA). The release of refractory radionuclides usually implies the presence of radioactive particles.

Windscale, UK (former Sellafield): During 1951 to 1957, about $20 \mathrm{~kg}$ U was released via the stacks of an air-cooled reactor due to corrosion. Fuel particles ranging up to 700 microns in length were identified [19), having flake-like structures significant different from those observed in the Chernobyl fallout [5]. The particles were inert towards leaching with $1 \mathrm{M} \mathrm{HCl} \mathrm{[4].} \mathrm{Following} \mathrm{the} \mathrm{fire} \mathrm{in} \mathrm{Pile} \mathrm{No} 1$ in 1957, localised heterogeneities in the environment were observed by autoradiography [20]. Particles varying within 20-500 $\mu \mathrm{m}$ were observed up $4 \mathrm{~km}$ from the site.

Chernobyl accident: About 6-8 tonnes of $\mathrm{UO}_{2}$ fuel were released into the atmosphere during the 
accident. Large fuel particles with variable composition of radionuclides deposited within the $30 \mathrm{~km}$ zone, while small-sized particles were identified up to $2000 \mathrm{~km}$ from the site [21]. Radioactive particles varying in composition, size, shape, structures and colours have been observed, from compact small-sized crystalline single particles to large amorphous aggregates. Using synchrotron-radiation X-ray micro-techniques, U-fuel particles released during the initial explosion were characterised by a core containing $\mathrm{UO}_{2}$ with surface layers of apparent reduced uranium, being relatively inert towards leaching. In contrast, U-fuel particles released during the fire were characterised by a $\mathrm{UO}_{2}$ core and surface layers of oxidised uranium being sensitive to leaching [5]. Based on ${ }^{90} \mathrm{Sr}$ mobilisation, the particle weathering constant (fraction dissolved from the particle per year) varied from 0.02 to $0.7 \mathrm{y}-1$ [22]; low for particles released during the explosion (deposited to the West of the site) and high for particles released during the fire (deposited to the North and South).

\subsection{Particles released via effluents from reprocessing plants}

Russian reprocessing plants: Following releases from Mayak PA in the Urals directly into the River Techa (1949-1951) and later into the reservoirs, radioactive particles containing $U$ and heavy metals have been identified in sediments and soils [23]. The presence of radioactive particles has also been reported from the Yenisey River due to releases from Krasnoyarsk Mining and Chemical Combine, Zheleznogorsk (Krasnoyarsk-26).

European reprocessing plants: Following releases from Sellafield, UK, into the Irish Sea, sediments especially outside the pipeline, have been significantly contaminated, also with particles. Radioautography has demonstrated the presence of large heterogeneities and $U$ particles have been identified. Due to accidental releases via the effluent at Dounreay, UK, in the 1960s, a certain number of radioactive particles is annually collected at beaches close to the site. The particles are relatively large with high activities $(\mathrm{MBq})$ made from $\mathrm{U}$ fuel and containing a series of fission products [unpublished]. No information on particles released from La Hague, France, and identified in the environment is available. However, a major fraction of radionuclides in the effluent from La Hague and Sellafield during normal operation has been associated with particles and colloids being relatively stable in sea waters [24].

\subsection{Particles from dumped nuclear material}

During 1959-1991, large amount of radioactive waste were dumped in the Abrosimov, Stepovogo and Tsivolky bays at Novaya Zemlya. In the close vicinities of dumped objects, especially containers, enhanced levels of Pu-isotopes and fission products in sediments were observe. Based on autoradiography, heterogeneities in the sediment samples reflected the presence of particles. Crud particles containing ${ }^{60} \mathrm{Co}$ were also identified by electron microscopy [25].

\section{CONCLUSIONS}

Past history has shown that a major fraction of refractory radionuclides released during serious nuclear event is present as radioactive particles. The matrix and refractory radionuclide composition will reflect the specific releasing source, while the release scenarios (e.g., temperature, pressures, redox conditions) will influence particle characteristics of relevance for weathering and subsequent remobilisation of associated radionuclides. Composition, particle size distribution and specific activity are essential for respiration and skin doses, while factors influencing particle weathering rates, such as matrix, size distribution, crystallographic structures, porosity, and oxidation states, are essential for long term ecosystem transfer. For areas affected by particle contamination, representative sampling may be questionable, leaching of actinides from particles prior to measurements may be partial and consequently the inventory may be underestimated. Until particle weathering occurs, remobilisation of associated radionuclides is delayed. With time, however, the remobilisation and soil-to-plant transfer of associated mobile radionuclides such as ${ }^{90} \mathrm{Sr}$ will increase. For areas contaminated by radioactive particles, short and especially long term impact assessments will therefore suffer from large overall 
uncertainties, unless the impact of particles and weathering processes are taken into account. To produce relevant information on source and release dependent particle characteristics advanced analytical micro-techniques are highly needed within radioecology.

\section{References}

[1] IAEA Co-ordinated Reseach Programme on radioactive particle. Report by an International Advisory Committee, (Tech. Doc., IAEA, Vienna 1999).

[2] Salbu, B., Encycl. Anal. Chem. (John Wiley \& Sons Ltd, Chichester, 2000) pp. 12993-13016.

[3] Bunzl, K., Analyst 122 (1997) 653-656.

[4] Oughton, D.H., Salbu, B., Brand, T.L., Day, J.P. and Aarkrog, A., Analyst, 118 (1993) 1101-1105.

[5] Salbu, B., Krekling, T. and Oughton D. H., Analyst 123 (1998) 843-849.

[6] Salbu, B., Krekling, T., Lind, O.C., Oughton, D.H., Drakopoulos, M., Simionovici, A., Snigireva, I., Snigirev, A., Weitkamp, T., Adams, F., Janssens, K. and Kashparov, V. A., Nucl. Instr. and Meth. A 467/21 (2001) 1249-1252.

[7] Simon, S., Jenner, T., Graham, J., \& Borcher, A., J. Radioanal. Nucl. Chem. 194 (1995) 197-205.

[8] Crocker, G.R., O’Connor, J.D., and Freiling E.C., Hlth Phys., 12 (1966) 1099-1104.

[9] Anspaugh, L.R. and Church, B.W., Hlth. Phys. 51 (1986) 35-51.

[10] Cooper, M., Burns, P., Tracy, B., Wilks, M. and Williams, G., J. Radioanal. Nucl. Chem. 177 (1994) 161-184.

[11] Dubasov, U.V., Krivohatskii, A.S., Kharitonov, K.V. and Ghorin, V.V., Radioactive contamination of the Semipalatinsk province ground and adjacent territories of the region after atmospheric nuclear tests in 1949-1962. Remediation and restoration of Radioactively-contaminated Sites in Europe. EU, Brussels (Proc. of the Int. Symp., Antwerp 1993. Doc. XI-5027/94. European Commission, Brussels, 1994) pp. 25.

[12] IAEA The radiological situation at the atolls of Mururoa and Fangataufa, (Report by an International Advisory Committee, IAEA, Vienna, 1998).

[13] AMAP-Arctic monitoring assessment programme. Arctic pollution issues: radioactive contamination. (Norwegian Radiation Protection Authority, Oesteraas,_Norway, 1997).

[14] Danesi, P.R., Markowicz, A., Chinea-Cano, E., Burkart, W., Salbu, B., Donohue, D., Ruedenauer, F., Hedberg, M., Vogt, S., Zaharadnik, P., Ciurapinski, A., J. Env. Radioact. 64 (2003) 143-154.

[15] Salbu, B., Janssens, K., Lind, O.C., Proost, K., Danesi, P.R., J. Env. Radioact. 64 (2003) 163-167.

[16] Salbua, B., Janssens, K., Lind, O.C., Proost, K., Gijsels, L. and Danesic P.R., J. Env. Radioact. In press

[17] Espinosa, A., Aragón, A., Hogdson, A., Stradling N. \& Birchall, A., Rad. Prot. Dos 7 (1998) 1-4.

[18] AMAP-Arctic monitoring assessment programme. Arctic pollution issues: radioactive contamination. (Norwegian Radiation Protection Authority, Oesteraas,_Norway). In press.

[19] Jakeman, D., Notes of the level of radioactive contamination in the Sellafield area arising from discharges in the Early 1950s. (UKAEA, AEEW Rep. No. 2104, AEE, Winfrith, 1986).

[20] Chamberlain, A.C., Sci. Tot. Environ. 63 (1987) 139-160.

[21] Kuriny, V.D., Ivanov, Y.A., Kashparov, V.A., Loschilov, N.A., Protsak, V.P., Yudin, E.B., Zhurba, M.A. and Parshakov, A.E., Ann. Nucl. Energy, 20 (1993) 415-420

[22] Kashparov, V.A., Oughton, D.H., Protsak, V.P., Zvarisch, S.I., Protsak, V.P. and Levchuk, S.E., Hlth. Phys. 76 (1999) 251-259.

[23] JRNEG-Joint Norwegian-Russian Expert Group. Sources contributing to radioactive contamination of the Techa River and areas surrounding the "Mayak" production association, Urals, Russia. (Norwegian Radiation Protection Authority, ISBN 82-993979-6-1, 1997) pp. 134.

[24] Salbu, B., Bjørnstad, H.E., Sværen, I., Prosser, S.L., Bulman, R.A., Harvey, B.R. and Lovett, M.B., Sci._Tot. Environ. 130/131 (1993) 51-63.

[25] Salbu, B., Nikitin, A.I., Strand, P., Christensen, G.C., Chumichev, V.B., Lind, B., Fjelldal, H., Bergan, T.D.S., Rudjord, A.L., Sickel, M., Valetova, N.K. and Føyn, L., Sci. Tot. Environ. 202 (1997) 185-198. 